Review

\title{
Application of small-angle X-ray and neutron scattering techniques to the characterisation of starch structure: A review
}

\author{
Jaroslav Blazek $^{\mathrm{a}, \mathrm{b}}$, Elliot Paul Gilbert ${ }^{\mathrm{a}, *}$ \\ a Bragg Institute, Australian Nuclear Science and Technology Organisation, Locked Bag 2001, Kirrawee DC, NSW 2232, Australia \\ ${ }^{\mathrm{b}}$ Food Futures Flagship, North Ryde Riverside Corporate Park, 5 Julius Avenue, North Ryde, NSW 2113, Australia
}

\section{A R T I C L E I N F O}

\section{Article history:}

Received 15 September 2010

Received in revised form 24 February 2011

Accepted 25 February 2011

Available online 3 March 2011

\section{Keywords:}

Small-angle X-ray scattering

Small-angle neutron scattering

Starch

Structure

Review

Lamella

Model

Granule

\begin{abstract}
A B S T R A C T
Scattering methods offer the unique potential to indirectly probe materials on length scales between the capabilities of modern crystallography and microscopy, thus bridging the gap in spatial resolution between the two groups of techniques. The most significant achievement of small-angle scattering techniques in starch science has been the quantification of the lamellar architecture of semicrystalline growth rings in native starch granules. The lamellae are structurally formed by side chains of amylopectin interspersed with amylose and their behaviour upon contact with water and varying temperature has been explained using a widely accepted 'liquid crystalline' model for starch. Scattering techniques have also been recently used to explore the structural factors in native and processed starches that determine resistance to acid and enzymatic hydrolysis. Attempts have been made to apply scattering methods in understanding more complex structures in starch-based food products. Application of these techniques that are traditionally not widely used in food materials science provides fascinating challenges and opportunities. With more basic scientific methods entering food technology, it is apparent that small-angle scattering techniques deserve their place in the multi-technique approach, which aims to understand the structural mechanisms governing starch processing and digestion, and makes it possible to design and select those processes which render desirable structural morphologies. This paper summarises previous investigations and the current status of research into the structure of native starch and starch-based systems using small-angle scattering techniques.
\end{abstract}

Crown Copyright @ 2011 Published by Elsevier Ltd. All rights reserved.

\section{Contents}

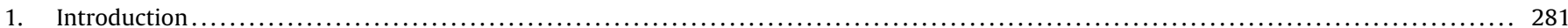

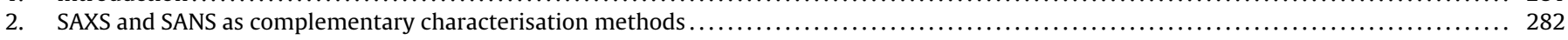

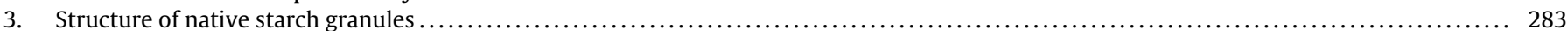

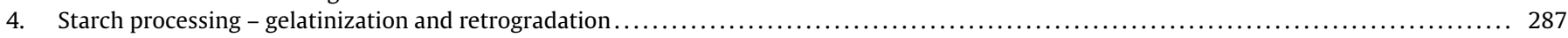

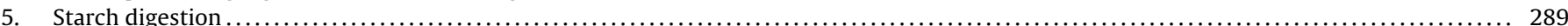

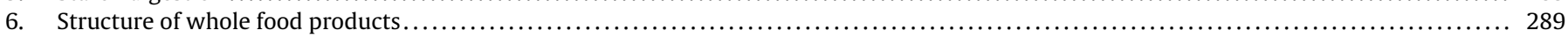

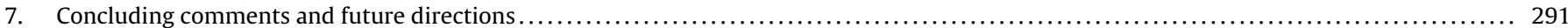

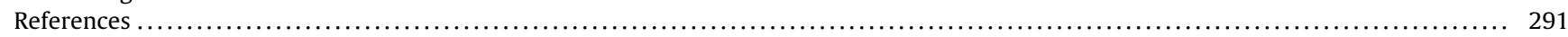

\section{Introduction}

The food industry is the largest on a global scale. Concerns around food, nutrition, bioenergy and the environment transcend national borders. There are significant challenges brought about by the increasing food demand driven by a growing population, rapidly changing food preferences and increasing demand for high

\footnotetext{
* Corresponding author. Tel.: +612 9717 9470; fax: +61 297173606.

E-mail address: elliot.gilbert@ansto.gov.au (E.P. Gilbert).
}

standards of food quality governed by economic developments, the impact of agriculture on the environment and the effect of climate change (Siddique, 2008).

Food represents some of the most complex examples of soft condensed matter. This arises from several factors: the complexity of components, the co-existence of multiple phases and the multitude of relevant characteristic time and length scales (Mezzenga, Schurtenberger, Burbidge, \& Michel, 2005). For companies wishing to design and produce new food products for the market-place, it is of increasing importance to understand the relationships between the form and functional properties of food constituents, includ- 
ing food structure and its sensory properties (Copeland, Blazek, Salman, \& Tang, 2009). The creation of novel functionalities of active ingredients in complex food systems requires knowledge of not only the structure of native agricultural materials but also the changes in their structure across a wide range of length scales brought about by food processing (Ubbink \& Mezzenga, 2006). It is the inherent complexity of modern food systems that calls for interdisciplinary scientific approaches to be applied.

Many food components, such as polysaccharides and proteins, are native polymeric materials. An understanding of the physical chemistry of these materials is largely based on polymer science principles. Nevertheless, the applications of these approaches to biopolymers is problematic for several reasons including natural variability and the complex multi-component formulation of most food products (starch itself being a complex two-component system, Belton, 2007; Limbach \& Kremer, 2006). Additionally, food polymers, in general, offer many particularly challenging hurdles to this understanding because they exhibit strong intra- and intermolecular interactions via the formation of hydrogen bonds and van der Waals interactions (Limbach \& Kremer, 2006).

Concepts in nanoscience provide a sound framework for developing an understanding of the interactions and assembly behaviour of food components from the nanoscale into the microstructure (Sanguansri \& Augustin, 2006). The same concepts have been applied in the study of starch structure and the influence of starch form on rheology, functional and nutritional properties at the macroscopic scale. In particular, the emphasis on developing new functionalities has rekindled interest in one of the most debated nutrients in the food industry - namely dietary fibre and resistant starch, which exist in many forms and whose structure-function relationship is poorly understood (Redgwell \& Fischer, 2005). This paper summarises both past achievements and the current status of research into the structure of native starch and starch-based systems using scattering techniques. Although a brief summary of starch structure and processing is given, it is not intended in this article to review the extensive literature on starch. For comprehensive treatises on starch structure, function and applications, the reader is referred to the compendia edited by Eliasson (2004) and by Yuryev, Tomasik, and Bertoft (2007), and the recent review by Copeland et al. (2009). Theoretical aspects of small-angle X-ray scattering can be found in the book by Glatter and Kratky (1982) while small-angle neutron scattering is well described by Higgins and Benoit (1994) and Hammouda (2008). The broader applications of neutron scattering in food science are covered in a recent the review paper by Lopez-Rubio and Gilbert (2009).

\section{SAXS and SANS as complementary characterisation methods}

Small angle scattering is the collective name given to the techniques of small angle neutron (SANS) and X-ray (SAXS) scattering. Both of these techniques are able to probe structures over a size range from approximately $1 \mathrm{~nm}$ to several hundreds of $\mathrm{nm}$. In each of these techniques X-ray photon or neutron radiation is (assumed to be) elastically scattered by a sample and the resulting distribution of scattered radiation is analysed to provide information about the size, shape and orientation of components in the sample. In contrast to the many other X-ray and neutron scattering methods, small-angle scattering is useful for structural determination at low resolution for systems that do not necessarily possess long-range or crystalline order.

Scattering is characterised by a law of reciprocity giving an inverse relationship between the size or dimension of the scattering object and the associated scattering angle (via Bragg's law to yield a real-space dimension, $d=2 \pi / q$ ). A small-angle scattering experiment measures the scattered intensity versus the scattering vector, $q$, which is defined as:

$q=\frac{4 \pi}{\lambda} \sin \theta$

where $\theta$ is half the angle through which the radiation is scattered and $\lambda$ is the wavelength of the incident radiation.

Typical X-ray or neutron wavelengths are small compared to structures on the nanoscale with the scattering occurring at small angle. At higher angles and correspondingly shorter length scales, wide-angle X-ray scattering (WAXS) is used to probe subnanometer dimensions. WAXS and X-ray diffraction (XRD) are often regarded as identical techniques in the literature. This is not strictly so. WAXS is conducted in transmission geometry, the same as SAXS; the scattering is measured as a function of angle and can be applied to materials that do not possess long-range order; on the other hand XRD may be performed in reflection or transmission geometry and is commonly used to characterise crystallographic structure. Ultra-small angle scattering techniques can be used to study structures with dimensions approaching approximately $10 \mu \mathrm{m}$ and are thus complementary to the range of microscopy techniques available. A broader comparison of scattering methods and complementary techniques with respect to the hierarchical structure of starch is shown in Fig. 1.

For scattering to occur from a sample, a contrast difference is required between the atoms or molecules in the object and its surroundings; this property depends on the type of radiation used. Differences in scattering are caused by chemical or physical inhomogeneities and thus one speaks of 'scattering particles'. SAXS measures variations in electron density distribution in a material. In the case of a binary system, the scattering intensity of X-rays is proportional to the difference in the scattering length densities between the two phases (the 'contrast').

Complementary to SAXS, SANS is also sensitive to structural inhomogeneities in materials at the nanometer scale. However, unlike X-rays that are scattered by electrons, neutrons are scattered by the atomic nuclei and the scattering contrast is associated with differences in neutron scattering length density. Here, the interaction between the scattering probe and atoms is via a nuclear interaction; this appears to vary pseudo-randomly across the periodic table but has high sensitivity to isotope. The classic example of this is between hydrogen (one proton in nucleus) and its heavier isotope, deuterium (one proton and one neutron). In this case, the extent of neutron scattering, defined by a length, is $-0.3742 \times 10^{-12} \mathrm{~cm}$ for hydrogen and $0.6671 \times 10^{-12} \mathrm{~cm}$ for deuterium. This length effectively defines the size of the nucleus but also represents the spatial extent of a pseudo-potential; the negative sign for hydrogen is thus associated with an effective attractive potential. This particular difference in scattering length is extremely valuable for the study of hydrogen-containing materials and forms the basis of a method known as contrast variation enabling structural features of different components to be distinguished via contrast matching one of them. This method is commonly based on selectively enhancing or reducing scattering from the sample or its components by using different ratios of $\mathrm{D}_{2} \mathrm{O}$ and $\mathrm{H}_{2} \mathrm{O}$, thus relying on the difference in scattering length of hydrogen from deuterium (Hammouda, 2008; Lovesey, 1984). This associated advantage of SANS makes SAXS and SANS ideal complementary techniques in the study of complex biological systems. It should be noted that contrast variation is also possible for X-rays. This may be achieved by adding contrasting agents to the solvent (sucrose, glucose or salts) or by conducting socalled anomalous SAXS experiments at a synchrotron in which several measurements are performed at different X-ray wavelengths across the absorption edge of an element in the sample 


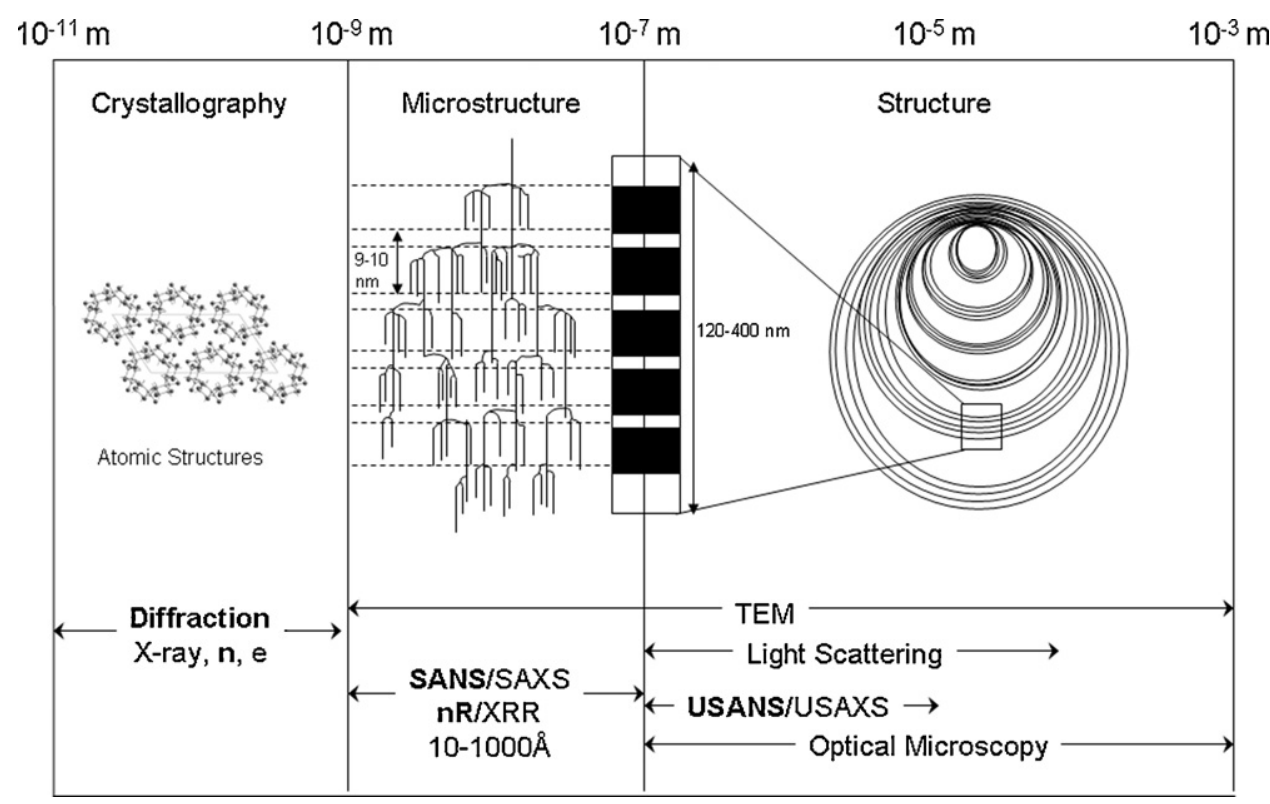

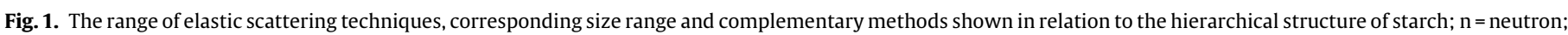
$\mathrm{e}=$ electron; $\mathrm{nR} / \mathrm{XRR}=$ neutron and $\mathrm{X}$-ray reflectometry, $\mathrm{TEM}=$ transmission electron microscopy; USANS/USAXS = ultra-SANS/SAXS

Reproduced with permission from Lopez-Rubio and Gilbert (2009).

under study (Haubold, Gebhardt, Buth, \& Goerigk, 1994; Svergun \& Koch, 2003).

Depending on existing knowledge of the system, small angle analysis may yield size, shape, mass and X-ray or neutron scattering length density from the scattering curve. The aim is to find a description of the system in real space, which, when Fourier transformed, adequately describes the scattering measured in reciprocal space e.g. to obtain a model-derived scattering curve that agrees with the experimental curve. Since there are a semi-infinite number of solutions to this problem, the model should also be based on parameters and associated solutions for them that are physically and chemically realistic. For this reason, information obtained from complementary materials characterisation methods is essential. An associated approach is to directly Fourier transform the data. Generic data fitting, model development and Fourier transform methods are discussed in more detail below.

The technique of SAXS dates back to the 1930s with one of the first observations of the intense scattering around the primary beam from carbon blacks (Brumberger, 1995). By the time of the classic monograph on SAXS by Guinier and Fournet (1955), much of the basic theory and instrumentation had been developed. Therein were extensive reports on its application to colloidal suspensions, macromolecular solutions including proteins and viruses, fibres, porous materials and metallic alloys, demonstrating that the method could yield information size, shape and internal structure of disordered and partially ordered systems (Guinier \& Fournet, 1955). The first SANS instrument was constructed over 35 years ago and currently both SAXS and SANS are well-established characterisation methods for nanostructural investigations in various materials (Hammouda, 2008). The experimental set-ups employ a large variety of different types of instruments using laboratory, synchrotron, spallation and reactor-based sources. Driven by the desire to look at the anisotropic small-angle scattering from various samples, slit systems with pinhole collimation were developed (Franks, 1955, 1958). To achieve more efficient data collection, twodimensional position-sensitive detectors were produced (Furuno, Sasabe, \& Ikegami, 1987; Hendricks, 1978). Such detectors yield very efficient data collection as the intensity is recorded for all azimuthal angles simultaneously, which has been crucial for many applications including dilute samples with relatively low scattered intensities. Non-crystalline biological systems benefited greatly from the development of synchrotron radiation sources that offer much higher spectral brilliance than conventional sources combined with their continuous energy tunability, small source size, small beam divergence and high beam flux (for review, see Koch, 2006); indeed, precautions need to be considered to prevent sample degradation due to such intense beam characteristics. In parallel to X-ray instrumentation, SANS instrumentation was developed which is almost entirely based on the pinhole geometry and twodimensional detectors. USANS is based on slit geometry design but the higher flux of synchrotron sources enables USAXS experiments to be conducted also in pinhole geometry.

As outlined in the next section, it is often desirable to measure scattering intensity on an absolute scale. However, there are several complications with obtaining absolute scattering intensity information because the number of photons scattered in the solid angle in the direction $2 \theta$ have to be normalized with respect to the number of photons transmitted through the sample. This implies the measurement of several parameters such as the sample thickness and transmission, incident flux, the solid angle of one pixel of the experiment, beam size and detector efficiency. Thus, to be able to compare scattering intensity from different samples, samples with known thickness and packing density are desirable.

\section{Structure of native starch granules}

Starch granules are semicrystalline particles ranging from 1 to $100 \mu \mathrm{m}$ in size and whose structure is dependent on botanic origin. The basic building block is a glycosyl monomer, measuring $0.3 \mathrm{~nm}$. Therefore any description of the native granules must cover the wide range of length scales. Due to the semicrystalline nature of starch granules, XRD, SAXS and SANS in combination with differential scanning calorimetry (DSC), nuclear magnetic resonance and optical, electron and atomic force microscopy have been used in parallel to reveal the complex ultrastructure of the granule, resulting in a prolific list of publications dating back to the early $1930 \mathrm{~s}$ (Tester, 1997; Tester, Karkalas, \& Qi, 2004).

Semi-crystalline native starch granules display a hierarchical structural periodicity (Fig. 2). Starch granules have a layered orga- 

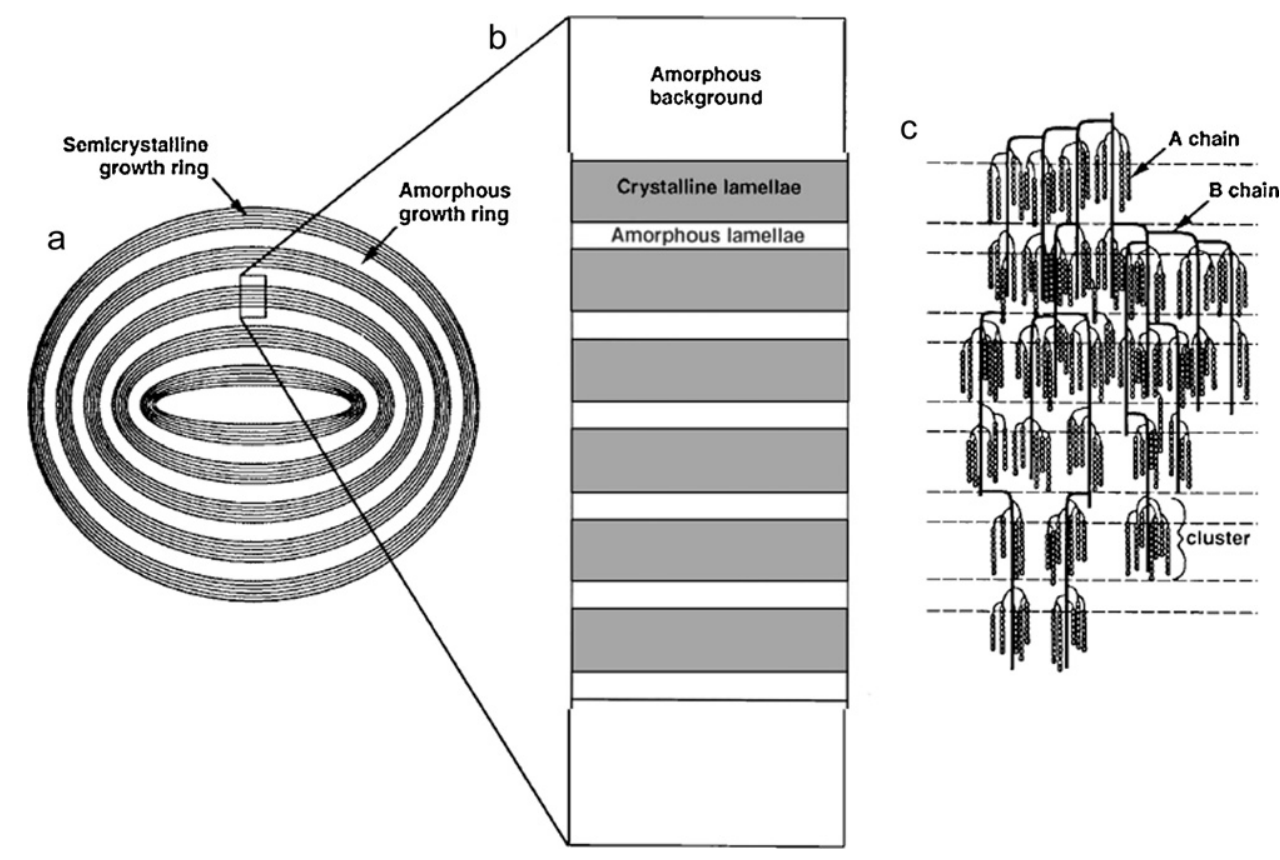

Fig. 2. Overview of starch granule structure: (a) the whole granule, (b) the lamellae, and (c) the polymer chains. Reproduced by permission of The Royal Society of Chemistry from Waigh et al. (1996).

nization with alternating amorphous and semi-crystalline radial growth rings of $120-400 \mathrm{~nm}$ thickness emanating from the hilum (Donald, Kato, Perry, \& Waigh, 2001). The amorphous rings consist of amylose and amylopectin in a disordered conformation, whereas the semi-crystalline rings are formed by a lamellar structure of alternating crystalline and amorphous regions with a regular repeat distance of 9-10 nm (Blanshard, Bates, Muhr, Worcester, \& Higgins, 1984; Cameron \& Donald, 1992; Sterling, 1962). The crystalline regions of the lamellae are thought to be formed by double helices of amylopectin side chains packed laterally into a crystalline lattice, whereas amorphous regions contain amylose and the amylopectin branching points. Amylopectin clusters may contain amylose molecules that pass through both the crystalline and amorphous layers. These "tie-chain" amylose molecules are proposed to be in a straightened conformation in crystalline regions and in a disordered conformation in amorphous regions (Kozlov, Blennow, Krivandin, \& Yuryev, 2007; Matveev et al., 1998).

The lamellar architecture of the semicrystalline growth rings is only detected by small-angle scattering in hydrated starch and not in dry starch granules. According to the currently most widely accepted model, this phenomenon can be rationalised by considering a 'liquid crystalline' model for starch (Cameron \& Donald, 1992; Waigh, Jenkins, \& Donald, 1996). In this model, side chains of amylopectin are considered to behave as a liquid-crystalline polymer (Cameron \& Donald, 1992; Donald, 2001; Jenkins, Cameron, \& Donald, 1993; Perry \& Donald, 2000a; Waigh, Gidley, Komanshek, \& Donald, 2000). In the presence of water, plasticization of amylopectin branch points, which act as flexible spacers, allows the double helices to be decoupled from the polymer backbone and aligned into lamellar register, resulting in a transition from the nematic (possessing orientational order but lacking positional order) to smectic (aligned in layers) phase (McArdle, 1989). Thus, in the hydrated form, correlations exist both laterally as shown by XRD and between the layers giving rise to small-angle scattering pattern. In the absence of water, the branch points become less flexible, pulling the double helices out of register and leading to the development of a nematic phase, in which the long range correlation between the layers is lost (Fig. 3). However, correlations persist within the double helices, which give rise to diffraction peaks in XRD patterns (Waigh, Perry, Riekel, Gidley, \& Donald, 1998).

Starch samples have been traditionally presented for scattering studies as starch slurries containing typically $45-55 \%(\mathrm{w} / \mathrm{w})$ water per starch (Cameron \& Donald, 1992; Yuryev et al., 2004). This may invoke difficulties when materials other than pure starches are studied. Most food materials often contain components that hydrate differently from starch and compete for water with starch, which makes it difficult to obtain comparable levels of starch hydration in different systems. One of the solutions is to use starch suspensions containing excess water above the settled starch granules or starch-based systems (Blazek et al., 2009). In any case, collected scattering data are normalized to sample transmission, and after subtracting background i.e. scattering in the absence of the sample e.g. empty capillary or capillary filled with water, they are averaged radially to generate one-dimensional scattering curves (Fig. 4). Such an approach is suitable for isotropic scatterers; however, if one were studying oriented materials, a sector averaging approach would be appropriate (for example, compaction of pre-gelatinized starch granules, Laity \& Cameron, 2010).

SAXS patterns from hydrated native starches show a broad scattering peak (Fig. 4), the position of which is reciprocally related to the average total thickness of the crystalline and amorphous regions in a lamellar arrangement in granular starches (known the lamellar repeat distance, long period or Bragg spacing; Waigh et al., 1996). In combination with other techniques, such as DSC and XRD, the thickness of the crystalline layer can be calculated (Blanshard et al., 1984; Waigh, Gidley, et al., 2000; Waigh, Kato, Donald, Gidley, \& Riekel, 2000; Waigh et al., 1998). The scattering intensity for a simple two phase system is proportional to the product of the relative fractions of each phase and the scattering length density difference (Glatter \& Kratky, 1982; Higgins \& Benoit, 1997). Accordingly, in terms of starch granules, the intensity of the scattering peak in starch thus depends on the amount of the ordered semicrystalline structures and/or on the differences in electron density between crystalline and amorphous lamellae with respect to the amorphous background (Yuryev et al., 2004). In general, there are two classes of methods that are used to extract parameters from 

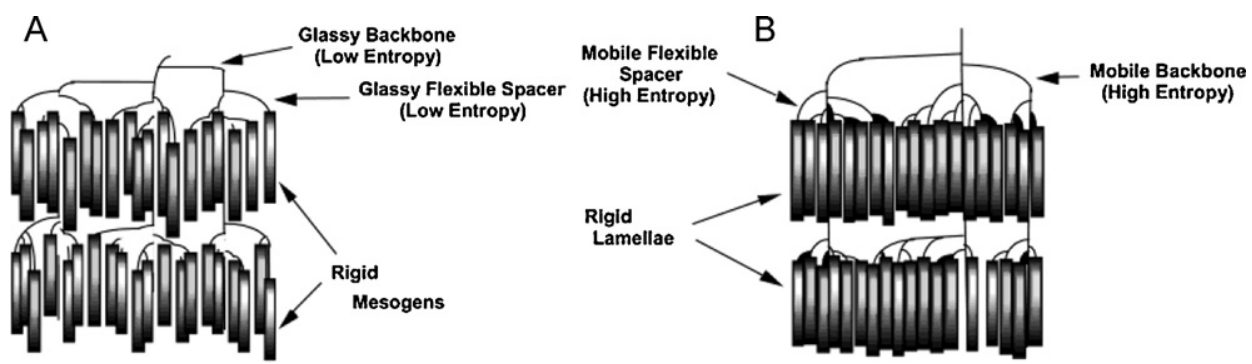

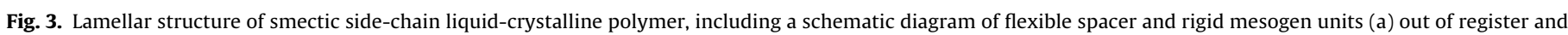
(b) in register.

Reproduced with permission from Daniels and Donald (2004).

the SAXS data. One class of methods is based on direct least-squares fitting of the observed intensity profile, whereas the other class is based on correlation and interface distribution functions using a Fourier transformed intensity profile.

In the methods that attempt to fit the observed intensity profile with a model, such as a simple paracrystalline model, the intensity profile calculated from the model is least-squares fitted to the observed intensity, and the various parameters of the model are iteratively refined (Cameron \& Donald, 1992; Murthy, Curran, Aharoni, \& Minor, 1991; Wang, Hsiao, \& Murthy, 2000). Donald's widely used model of an ideal paracrystalline system assumes three different electron densities (Fig. 2): crystalline and amorphous for the finite stacks of semi-crystalline lamellae, and a further amorphous background (Cameron \& Donald, 1992). Parameters describing two electron density differences together with the average repeat distance, the crystallinity, a factor related to the width of the distribution of lamellar thicknesses, and the number of repeats in a single stack comprise the model that is fitted to the experimental data (Cameron \& Donald, 1992; Vonk, 1978; Wenig \& Bramer, 1978). This three phase model is assumed to be isotropic, i.e. the lamellar layers are assumed to be perpendicular to the lamellar repeat direction but many such lamellae exist in the sample overall that are oriented isotropically. In this model, amylopectin double helices (the mesogens) form crystalline regions, the branch points of amylopectin (the spacers) are located in the amorphous region of the lamellae, and the amorphous growth ring (amorphous background) must contain any amylose since it is assumed this does not crystallize within the granule itself (Balta-Calleja \& Vonk, 1989; Koberstein \& Stein, 1983; Strobl \& Schneider, 1980). It should be noted that this general view on the localization of amylose within the starch granule may be over-simplistic as the involvement of amylose in crystallites differs between A-type and B-type starches as shown by Saibene and Seetharaman (2010).
The original paracrystalline model of Cameron and Donald (1992) does not account for the effect of deviations from an ideal lamellar structure (i.e. infinite-sized clusters of parallel layers of alternating electron densities) on the small-angle scattering curve. Distortions giving rise to structures containing concentric layers were shown to have little effect on lamellar morphology, whereas corrugation of the surfaces causes minor modifications (Vonk, 1978). An approach to account for these deviations is to invoke the model proposed by Daniels and Donald (2003), which allows the planes of the semi-crystalline lamellae to fluctuate both along the layer repeat direction and along the transverse layer direction. Such fluctuations introduce bending of the layers and splay of the double helical units, which are treated as mesogens (Daniels \& Donald, 2003, 2004). This requires two parameters additional to the original paracrystalline model describing the deviation away from ideal lamellar behaviour (via a correlation function) and the angular deviation away from the preferred direction along the lamellar normal. Even greater complexity could be incorporated through the inclusion of a thickness distribution function for the individual crystalline and amorphous regions and a finite thickness for the transition between crystalline and amorphous region (Agamalyan et al., 1992). Comparison of the scattering parameters with amylopectin chain-length data in various starches has been achieved, showing correlations between mesogen length and layer bending with the branching architecture of amylopectin (Noda et al., 2009; Sanderson, Daniels, Donald, Blennow, \& Engelsen, 2006; Vermeylen, Goderis, Reynaers, \& Delcour, 2004). While additional parameters to the original paracrystalline model evidently enhance the ability to fit the scattering data, the reality is that there remains significant uncertainty on their precision. However, the more complex model could work well when additional scattering information is available, such as that obtained with combined neutron contrast variation methods and the ability to conduct subsequent simul-

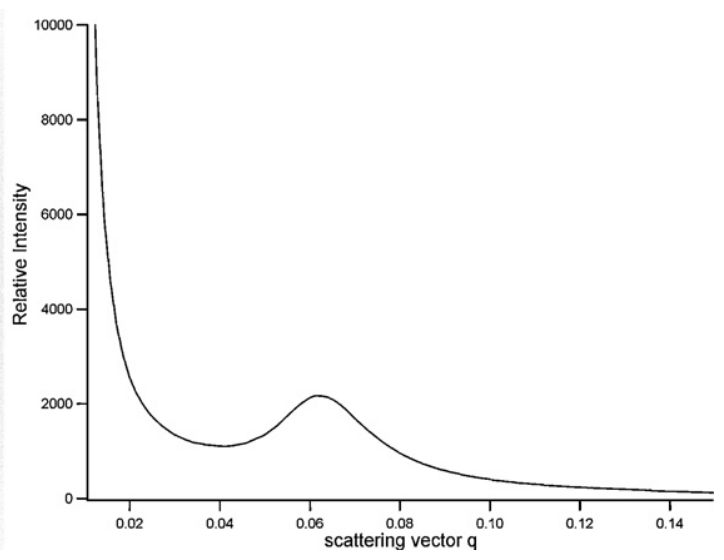

Fig. 4. Scattering pattern from regular maize starch and corresponding SAXS curve showing relative intensity vs. scattering vector. 
taneous global refinement. The latter enables scattering patterns collected at different contrast to effectively provide constraints on the additional parameters in the Daniels and Donald model. The challenge now is the ability to fit scattering data over a more extensive size range either through lower $q$ SAXS/SANS studies or through the application of ultra-small-angle scattering methods.

In another class of methods based on a correlation function, the intensity data are Fourier transformed, and the resulting one dimensional correlation function is interpreted in terms of lamellar morphology to obtain structural parameters such as lamellar repeat distance, hard (crystalline) and soft (amorphous) block thicknesses, the width of the transition layer and electron density contrast (Balta-Calleja \& Vonk, 1989; Schmidt-Rohr, 2007; Strobl \& Schneider, 1980; Verma, Marand, \& Hsiao, 1996; Vonk, 1973).

Wang et al. (2000) compared the intensity profile analysis and correlation function methods for studying the lamellar structures of semicrystalline polymers using SAXS. The calculated value of the thickness of the crystalline lamellae by the intensity profile analysis has been found to be consistently greater than that obtained from correlation function analysis. However, it should be noted that the correlation function approach assumes that the low $q$ and high $q$ behaviour can be adequately described by Guinier and Porod scattering, respectively. This is because the Fourier transform of the data requires 'knowledge' of the scattering function between $q=0$ and infinity to avoid significant truncation effects. The assumption that there is an observable Guinier region is problematic as scattering features from structures larger than the lamellae e.g. growth rings, surface scattering, will certainly influence the low $q$ region. As such, differences in values obtained from the two approaches are expected. The correlation function analysis was found to provide meaningful results even when the lamellar peak is not clearly defined (Wang et al., 2000).

Intensity, position and width of the SAXS peak can also be determined by more empirical methods such as the graphical method as described by Yuryev et al. (2004) or by fitting the data to equations that describe the SAXS peak and account for underlying diffuse or interfacial scattering (Blazek \& Gilbert, 2010; Chanvrier et al., 2007; Lopez-Rubio, Htoon, \& Gilbert, 2007; LopezRubio, Flanagan, Shrestha, Gidley, \& Gilbert, 2008). The latter fitting approach employs a power-law function to describe the underlying diffuse scattering at low $q$, a Gaussian/Lorentzian peak (or combination thereof) to fit the lamellar peak around $0.06 \AA^{-1}$ and a Gaussian peak for the second order reflection peak around $0.13 \AA^{-1}$ (Blazek \& Gilbert, 2010).

A simple paracrystalline model has been found to work well for many studies with interlamellar spacings having been found to be remarkably constant across a large number of starches (Blazek et al., 2009; Jenkins et al., 1993; Kozlov, Blennow, et al., 2007; Vandeputte \& Delcour, 2004; Yuryev et al., 2004). However, recent studies using small-angle scattering complemented by other techniques have increased our understanding of the influence of amylose located within amylopectin clusters in native starch granules from multiple sources including genetically modified and mutant starches (for example, Blazek et al., 2009; Saibene \& Seetharaman, 2010).

SAXS investigations of starches extracted from different plant sources have revealed the continuous decrease in the intensity of scattering maximum with increasing amylose content in native starches (Bocharnikova et al., 2003; Jenkins \& Donald, 1995; Kozlov, Blennow, et al., 2007; Kozlov, Krivandin, et al., 2007; Sanderson et al., 2006; Yuryev et al., 2004). There are several hypotheses for the explanation of this phenomenon based on the localization of amylose and amylopectin in the crystalline and amorphous regions of the lamellae (Yuryev et al., 2004). The most accepted theory accounts for the decrease in scattering intensity with increasing amylose content by a decrease in the electron density difference between crystalline and amorphous regions of the lamellae. This

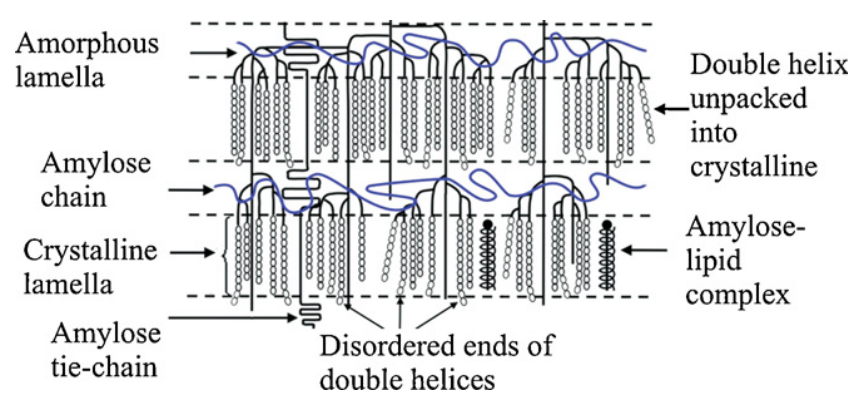

Fig. 5. Model of the lamellar architecture of amylose-rich starch granules. Reproduced with permission from Kozlov et al. (2007b).

in turn may be caused by several factors as outlined by Yuryev et al. (2004): co-crystallization of amylose macromolecules with amylopectin side-chains within crystalline lamellae, accumulation of amylose chains oriented transverse to the lamellar stack within amorphous lamellae, and accumulation of amylose tie-chains both inside crystalline and amorphous lamellae (Fig. 5). Disordered ends of amylopectin double helices and/or double helices not participating in the formation of crystals are also proposed to be contributing factors to defects of the crystalline regions and, in turn, to greater disorder in the packing of the lamellar structure (Blazek et al., 2009; Koroteeva, Kiseleva, Krivandin, et al., 2007; Koroteeva, Kiseleva, Sriroth, et al., 2007; Kozlov, Krivandin, et al., 2007; Salman et al., 2009; Yuryev et al., 2004). There is a general agreement across most recent studies that defects brought about by starch-synthesizing enzymes depend both on differences in environmental conditions during plant growth and genetic background of the cultivars. It is critical to emphasize the importance of employing XRD and highsensitivity DSC in line with small-angle scattering in the search for the correct explanation for individual studied systems. Apart from studying nanostructure of various starch cultivars, SAXS was also found to be useful in determining structural changes that occur in starches during storage (Chanvrier et al., 2007; Vaananen et al., 2003) and in elucidating differences in organization between large and small wheat starch granules (Salman et al., 2009).

The advantage of SANS over SAXS in its ability to selectively enhance, reduce or match scattering from sample components has been demonstrated by Jenkins and Donald (1996) in their study aimed in understanding the distribution of water within waxy maize starch granules via solvent contrast variation (Table 1 ). Using starch granules dispersed in water with different $\mathrm{D}_{2} \mathrm{O}$ contents allowed the quantification of water contents in each of the three regions modelled by SAXS. Apart from examining the distribution of water in different parts of the granule, SANS has also been used to quantify the molecular densities in different regions of the granule

Table 1

Neutron and X-ray scattering length densities for crystalline and amorphous starch fractions and water (Waigh et al., 1996). Physical densities of crystalline and amorphous starch are taken to be 1.72 and $1.59 \mathrm{~g} \mathrm{~cm}^{-3}$ respectively and assuming complete exchange of labile hydrogen with deuterium in the case of heavy-water hydration. For example, a crystalline region containing $90 \%$ mole fraction of starch and $10 \%$ normal water would have a neutron SLD of $((0.90 \times 3.93)+(0.10 \times-0.56)) \times 10^{10} \mathrm{~cm}^{-2}=3.48 \times 10^{10} \mathrm{~cm}^{-2}$.

\begin{tabular}{lcc}
\hline Compound & $\begin{array}{l}\text { Neutron SLD } \\
\left(10^{10} \mathrm{~cm}^{-2}\right)\end{array}$ & $\begin{array}{l}\text { X-ray SLD } \\
\left(10^{10} \mathrm{~cm}^{-2}\right)\end{array}$ \\
\hline Crystalline (hydrated with $\left.\mathrm{H}_{2} \mathrm{O}\right)$ & 2.01 & 15.5 \\
Crystalline (hydrated with $\left.\mathrm{D}_{2} \mathrm{O}\right)$ & 3.93 & 15.3 \\
Amorphous (hydrated with $\left.\mathrm{H}_{2} \mathrm{O}\right)$ & 1.86 & 14.4 \\
Amorphous (hydrated with $\left.\mathrm{D}_{2} \mathrm{O}\right)$ & 3.64 & 14.1 \\
$\mathrm{H}_{2} \mathrm{O}$ & -0.56 & 9.43 \\
$\mathrm{D}_{2} \mathrm{O}$ & 6.38 & 9.43 \\
\hline
\end{tabular}


and compare these among varieties (Donald et al., 2001; LopezRubio \& Gilbert, 2009; Perry \& Donald, 2000b).

Although different levels of organization within the granule are broadly understood, there are still unknowns - for instance the respective contributions of amylose and amylopectin to crystallinity, the distribution of ordered and unordered areas in the granule and architecture at the length scales between the lamellar size range $(10 \mathrm{~nm})$ and growth rings $(120-400 \mathrm{~nm}$ ) (Donald et al., 2001). At least two models have been proposed to describe arrangements at these length scales; these are Oostergetel's model of superhelices (Oostergetel \& van Bruggen, 1993) and the theory of blocklets (Baker, Miles, \& Helbert, 2001; Parker, Kirby, \& Morris, 2008; Gallant, Bouchet, \& Baldwin, 1997; Peng, Zhongdong, \& Kennedy, 2007; Tang, Mitsunaga, \& Kawamura, 2006). The dimensions quoted for the blocklets, typically $50-250 \mathrm{~nm}$, are sufficiently large that their impact on the lamellar peak is likely to be small. The existence of blockets still remains to be proven and it may be anticipated that ultra-small and small angle scattering may play a role in this regard together with complementary techniques such as AFM (Parker et al., 2008; Ridout, Parker, Hedley, Bogracheva, \& Morris, 2004). Since the recognition that a liquid crystalline analogy might be valuable for the interpretation of granular starch structure, the idea has been further developed and applied to many starches from various origins. Nevertheless, this schematic representation of the packing within the granule must not be taken too literally. Small angle scattering provides bulk information and can only provide average information over many lamellae as well as over many granules and thus local variations are necessarily lost in this averaging process. This can be addressed to some extent by microfocus scattering and diffraction experiments ensuring special care to avoid beam damage (Buleon et al., 1997; Buleon, Gerard, Riekel, Vuong, \& Chnazy, 1998; Nishiyama, Putaux, Montesanti, Hazemann, \& Rochas, 2010; Popov et al., 2009; Waigh et al., 1997; Waigh, Donald, Heidelbach, Riekel, \& Gidley, 1999). Waigh et al. (1999) found good agreement between the scattering patterns from parts of the granules and the values predicted from a superhelical lamellar model containing cumulative disorder along its axis. At a higher hierarchical level, growth rings are drawn simplistically as being continuous around the granule but this is unlikely to be accurate.

\section{Starch processing - gelatinization and retrogradation}

Approximately, 60 million tonnes of starch are extracted annually worldwide from various cereal, tuber and root crops, of which roughly $60 \%$ is used in foods, as texturisers, gelling agents, thickeners, moisture-retainers; $40 \%$ is used in pharmaceuticals and non-edible purposes, such as fertilisers, seed coatings, paper, cardboard, packing material, adhesives, textiles, fabrics, diapers, bioplastics, building materials, cement, and oil drilling (Burrell, 2003; Copeland et al., 2009). Although native starch granules are used in some of these applications, starch for food applications is generally consumed after processing. An excess of water and high temperature during processing results in starch gelatinization with destruction of its granular structure. However, in several low moisture food products such as biscuits, the granular structure of starch can be retained. The effect of processing on the structure of starch in food can vary considerably, affecting the sensory properties (texture, visual aspect and flavour) as well as nutritional ones (Annison \& Topping, 1994). Therefore, starches with a wide range of functional properties are needed to ensure fitness-for-purpose for such a diverse range of end uses.

Various components of processed foods are generally not found in their natural environment and conditions but in a state far from equilibrium (Mezzenga et al., 2005). To charac- terise the complexity of the changes brought about by processing, laboratory tools such as the Rapid Visco Analyser (Newport Scientific) or Brabender Amylograph have been used to describe food component performance. Their use does not require extensive knowledge of physical chemistry and rheology since their goal is to provide qualitative information related to process adequacy and quality control. More objective experimental approaches with necessary adaptations are now needed, including scattering techniques, that help relate food microstructure to functionality.

Processing almost invariably involves the application of heat and moisture for varying lengths of time. When starch granules are heated in excess water, starch granules swell and change their size and shape, blocklet-like structures are dispersed, crystalline regions are irreversibly disrupted, birefringence is lost as double helices unwind and starch becomes soluble (Cameron \& Donald, 1992; Jenkins \& Donald, 1997b, 1998; Waigh, Gidley, et al., 2000). This molecular disordering known as gelatinization is more complex than a simple granular order-to-disorder transition and understanding the gelatinization mechanisms have evolved simultaneously with the knowledge of granular structure. The process of granule disruption is initiated by swelling of amorphous growth rings within the granule accompanied by leaching of amylose from the granule (Blanshard, 1987; Donovan, 1979). After a significant amount of water enters the amorphous regions, providing sufficient stress through connectivity of molecules from the amorphous growth ring to the semi-crystalline lamellae, disruption of starch crystallites can be evidenced by the loss of crystallinity. Current understanding of gelatinization is based on the glass transition and liquid-crystalline theories, considering amylopectin molecules to be a liquid-crystalline polymer with side-chains (Jenkins \& Donald, 1998; Waigh, Gidley, et al., 2000). Therefore, gelatinization is hypothesized to result from moisture and heat-driven helix-coil transitions and transformations from a glassy nematic phase to a plasticized smectic phase of amylopectin helices (Pikus, 2005; Waigh, Gidley, et al., 2000). It has been suggested that either the crystalline disruption occurs before or after the disordering of double helices depending on starch type (Colonna \& Mercier, 1985), although more recent studies suggest that both double-helical order and crystalline structure are lost concurrently during heating (Waigh, Gidley, et al., 2000).

SAXS allows the absorption of water into different regions of starch granule to be monitored through determining the relative electron densities of the crystalline and amorphous regions and the amorphous background (Cameron \& Donald, 1992, 1993b). In the early stages of gelatinization, the electron density contrast between the crystalline and amorphous lamellae was shown to increase with time and temperature as water is absorbed into the amorphous lamellae allowing the crystalline regions to evolve from the nematic to the smectic phase (Fig. 6) (Cameron \& Donald, 1992; Gebhardt, Hanfland, Mezouar, \& Riekel, 2007; Jacobs et al., 1998; Jenkins et al., 1994; Vermeylen et al., 2006a, 2006b). The background material was shown to absorb water faster and to a greater extent than the amorphous lamellae, a fact attributed to the lower degree of physical constraint in this region (Cameron \& Donald, 1992, 1993a). Subsequently, contrast between the crystalline and amorphous lamellae was shown to decrease, indicating that significant disruption of the crystalline material occurs (Cameron \& Donald, 1992). When the melting temperature of the crystallites is reached, the crystalline and lamellar order is lost as is evidenced by the loss of the characteristic lamellar scattering peak. Methods of analysis of scattering curves without characteristic peaks are discussed further in this chapter. SAXS also confirmed that the elevation of the gelatinization temperature caused by the addition of sugars and other non-aqueous solutes is due to a reduced level of 

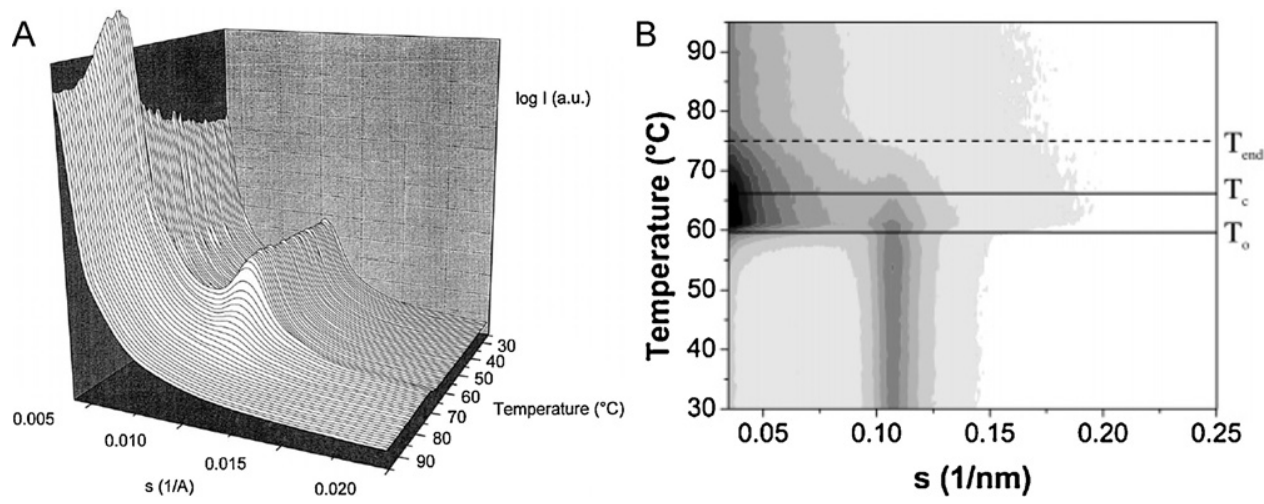

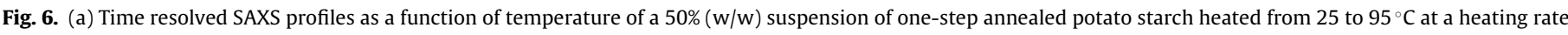

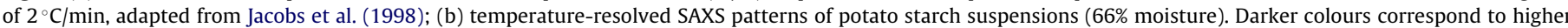
intensities. DSC onset $\left(T_{0}\right)$, conclusion $\left(T_{\mathrm{c}}\right)$, and end temperatures $\left(T_{\text {end }}\right)$ are indicated by horizontal lines.

Reproduced with permission from Vermeylen et al. (2006a).

solvent plasticization of the amorphous growth ring region (Perry \& Donald, 2002)

The annealing of starch - defined as the incubation of granular starch in excess water at a temperature above the glass transition but below the gelatinization temperature - induces significant effects on starch physicochemical properties. Static SAXS measurements have shown that the dimensions of crystalline and amorphous lamellae in starch granules are unaffected by annealing but SAXS peaks are intensified (Jacobs et al., 1998). Annealed starches, in contrast to native starches, do not display an increase in lamellar peak area at the onset of gelatinization. The effects following annealing are interpreted as decreased water absorption during gelatinization. Annealing leads to a retardation of the initial swelling and cooperative melting of the granules, without altering the stability of the most perfect crystallites (Jacobs et al., 1998). Gamma irradiation has the opposite effect on the structure of native starch granules to annealing; changes in the scattering curves were shown to be connected with the destruction of longrange ordering in starch granules (Ciesla, Zoltowski, \& Mogilevski, 1992).

Small-angle scattering studies of the behaviour of starches during gelatinization and retrogradation are mostly analysed on the basis of the fractal concept. The essential property of a fractal is that its structure appears to be self-similar when examined over a range of magnifications. Fractals have become an important topic in many fields of physical and biological science, including the analysis and interpretation of the small-angle scattering data from porous media including rocks (Avnir, 1989; Mandelbrot, $1977,1983)$. One of the most important features of the small-angle scattering from fractal systems is that many properties of these systems can be described by quantities that are proportional to a power of another quantity. In particular, the intensity $I$ of the small-angle X-ray or neutron scattering from many disordered systems has been found to be proportional to a negative power of the scattering vector $q$. This kind of scattering, expressed as $I \propto q^{\alpha}$, is often called 'power-law' scattering (Martin \& Hurd, 1987; Schmidt, 1991). When fractal relations are observed from scattering experiments, i.e. there is a linear relationship between $\log I$ and $\log q$, it is possible to interpret the scattering from the value of the exponent, $\alpha$. In general, for $-4<\alpha<-3$, the scattering is interfacial and defined as 'surface fractal'. In the case of $-1<\alpha<-3$, the scattering is classified as a 'mass fractal'. This range includes the scattering from branched systems such as gels or networks with a slope of $q^{-2}$ corresponding to Gaussian polymer chains. Having said this, other, non-fractal, interpretations exist for such slopes e.g. $q^{-2}$ behaviour may be associated with scattering from dilute and isotropic sheet-like objects. A more extended treatment of fractals is included in the review by Martin and Hurd (1987) and Beaucage (1996).

The main scattering source from low moisture native starches can be interpreted as a surface fractal obeying a power law with an exponent of ca. -4 (Lopez-Rubio et al., 2007). When the starch granules swell, the surface fractal behaviour is observed only at very low angles, and on heating it disappears. For gelatinized starches, the whole scattering pattern was shown to obey the power law with the power of around -2 . The resulting (gel) network of gelatinized starch molecules behaves as a 'mass fractal' (Suzuki, Chiba, \& Yano, 1997; Vermeylen et al., 2006a). Amylose was shown to play a major role in determining the dimensions of the self-similar structures that develop during gelatinization (Vermeylen et al., 2006a)

On cooling starch molecules retrograde gradually into semicrystalline aggregates that differ in form from native granules. Starch-rich foods that have been cooked and cooled often contain a substantial amount of retrograded starch (Copeland et al., 2009). Scattering techniques have been used to a limited extent for studies of the nanostructure of amylose gels and gelatinized starches (I’Anson, Miles, Morris, \& Ring, 1988; Müller et al., 1995; Suzuki et al., 1997). Amylose gelation was shown to proceed by phase separation into a polymer-rich network phase interpenetrated by a polymer-deficient phase, followed by crystallization (I'Anson et al., 1988). Similarly to gelatinized starch systems, retrograded gels can be interpreted on the basis of fractals. When re-organization following gelatinization reaches a sufficient level of ordering, Bragg peaks can be observed (Suzuki et al., 1997).

Gelatinization and retrogradation are known to be significantly influenced by additives. One of the most important interactions in starch systems is the one between amylose and lipids, altering both the functional and nutritional characteristics of starch-containing food products. Lipids have the ability to reduce the digestibility of gelatinized starch by inducing single helical conformation of the amylose chain. On the other hand, complexation of starch with lipids generally inhibits or slows down the process of retrogradation, thus decreasing resistance of starch to digestive enzymes as compared to highly resistant retrograded starch. SAXS has proven to be applicable for studying the effect of unsaturated fatty acids on the structure of amylose-lipid inclusion complexes (Zabar, Lesmes, Katz, Shimoni, \& Bianco-Peled, 2009). Varying the complexation temperature and fatty acid composition has been shown to have an effect on the peak observed in the SAXS curves. It was noted that the decreased degree of fatty acid unsaturation induced the formation of more organized and well-defined structures (Zabar et al., 2009). 


\section{Starch digestion}

The importance of starch in the human diet arises from being one of the main constituents of native and processed foods. Most of the starch in the diet is digested to glucose, which is readily absorbed into the blood stream. Starch not digested in the small intestine is referred to as resistant starch, which has been associated with nutritional benefits through moderating the glycaemic response and being a fermentable substrate in the large intestine to produce short chain fatty acids. These molecules are beneficial for the correct functioning of the bowel and have been related to the prevention of several diseases (Cassidy, Bingham, \& Cummings, 1994; Hylla et al., 1998). Animal feed is often required to be highly digestible to provide cost effectiveness; however, in the human diet, recent awareness of the importance of healthy food has led to an increased demand for health-promoting food additives such as slowly digestible and resistant starches.

Digestion of starch requires small intestinal alpha-glucosidic activities provided by the two soluble amylases and four enzymes bound to the mucosal surface of enterocytes. The susceptibility of starch granules to degradation by amylases depends on the source of the starch and of the amylase. Dramatic changes in starch digestibility are brought about by food processing due to gelatinization, retrogradation and chemical modification of starch. It is somewhat ironic that granular starch has received more attention in structural characterisation upon digestion despite most starch in the human diet being consumed following at least one stage of processing. To the best of our knowledge, there are only a few smallangle scattering studies of acid and enzymatic hydrolysis of native starch granules and processed starch-based foods.

Changes of the lamellar architecture and crystalline structures during acid hydrolysis have been studied using simultaneous small and wide angle X-ray scattering. Muhr, Blanshard, and Bates (1984) and Jenkins and Donald (1997a) showed that the lamellar SAXS peak becomes less pronounced upon acid hydrolysis of native starch granules whereas the WAXS peaks become more intense. Jenkins and Donald (1997a) explained these observations by considering preferential destruction of the amorphous background (growth-ring) region during the hydrolysis process. Similarly, a paracrystalline model (Cameron \& Donald, 1992) was applied to describe the effects of alkaline treatment on the ultrastructure of C-type starch granules and revealed significant compression of semicrystalline growth rings upon washing of starch in alkaline solution (Thys et al., 2008).

As trends in the food industry have been increasingly influenced by nutritional concerns in addition to technological criteria, interest has become focused on understanding the enzymatic digestion of native starch granules. There are few reports in the literature that use SAS to characterise changes of the lamellar architecture caused by the action of starch-degrading enzymes. Our understanding of the progress of enzymatic digestion of granular starches has been enhanced with the help of techniques such as XRD, DSC, NMR and microscopy. Many unanswered questions remain regarding the mode of hydrolysis (exo- or endo-corrosion), differences in digestion between A-type and B-type starches, and whether amorphous regions are preferentially digested (Gallant, Bouchet, Buleon, \& Perez, 1992) or crystalline and amorphous material is digested side-by-side (Zhang, Ao, \& Hamaker, 2006; Zhang, Venkatachalam, \& Hamaker, 2006).

In the recent work of Chanvrier et al. (2007), several maize and wheat starch varieties differing in amylose content were studied by SAXS in the native form and post-enzymatic digestion. The authors fitted the data to a power-law plus Lorentzian function and confirmed the general trend of decreasing intensity of the lamellar peak with increasing amylose content, explained by the accumulation of defects within the lamellar architecture. Digestion of the raw starches was shown to lead to the decrease in the intensity of the lamellar peak, which was accompanied by decreasing crystallinity as determined by XRD. Similarly, Lopez-Rubio et al. (2007) reported that the lamellar peak in a raw high-amylose maize starch, Gelose 80 , did not change significantly during $\alpha-$ amylolysis. The absolute value of the slope of the USAXS/SAXS curves was reported to decrease as a result of digestion, indicating an increase in surface roughness of the starch granules after digestion. Complementary to SAXS analysis, Lopez-Rubio et al. (2007) showed that digestion of raw Gelose 80 led to a decrease in the XRD crystalline order, which contrasts with previous observations that amorphous parts are preferentially hydrolyzed during digestion (Hoover \& Manuel, 1995). It is possible that such discrepancies may be caused by the fact that A-type and B-type starches are affected differently by enzymatic digestion as noted by Aggarwal and Dollimore (1998) who reported that partial digestion by glucoamylase caused corn, wheat and rice starch granules to gain more crystalline character and increase in gelatinization temperature, whereas crystallinity and thermal properties of potato starch remained unaffected, which was attributed to a greater resistance of the surface of potato starch granules to enzymatic attack than A-type starches.

In a follow-up study, Blazek and Gilbert (2010) studied enzymatic digestion of six starches of different botanical origins in real time by in situ time-resolved small-angle neutron scattering (SANS) and complemented by the analysis of native and digested material by XRD, SAXS, DSC, XRD and SEM. It was shown that the lamellar peak intensity gradually decreased and low- $q$ scattering increased in the course of digestion. These trends were more substantial for A-type than for B-type starches and were explained by preferential digestion of the amorphous growth rings. Hydrolysis of the semi-crystalline growth rings was described on the basis of a liquid-crystalline model for starch considering differences between A-type and B-type starches in the length and rigidity of amylopectin spacers and branches. As evidenced by differing morphologies of enzymatic attack among varieties, the existence of granular pores and channels and physical penetrability of the amorphous growthring were assumed to further affect the accessibility of the enzyme to the substrate. Blazek and Gilbert (2010) concluded that the combined effects of the granule microstructure and the nanostructure of the growth-rings influence the opportunity of the enzyme to access its substrate and thus determine the enzymatic digestibility of granular starches more than the absolute physical densities of the three granular regions.

\section{Structure of whole food products}

Although much research has been carried out on the characterisation of the crystalline and the lamellar structure of native starches, very little is known on the structure of processed starch. Shamai, Shimoni, and Bianco-Peled (2004) used SAXS to explore the structure of the crystalline elements of resistant starch fractions prepared from high-amylose corn starch. The authors applied the "modified lamellar model" (Cameron \& Donald, 1992; Wenig \& Bramer, 1978) to fit the scattering data and, although a good fit to the theoretical model was obtained, they noted that the multitude variables lower the sensitivity of the different parameters and reduce the accuracy of the model. The sensitivity of this model was found to be very low to fit scattering data from the resistant starch fractions, which lacked any well pronounced peaks. Instead, the authors used two other models, i.e. a "dilute system of individual lamellae" (flat particles with finite thickness and that are assumed to be extremely large in the other two dimensions; Glatter \& Kratky, 1982) and the "two-phase non-particulate system" (Debye-Beuche model, a system consisting of one phase composed of domains with sharp interfaces randomly distributed in a second phase; Debye 
\& Bueche, 1949). Their results showed that retrogradation at low temperature leads to formation of polymorph B with crystallinity lower than that of the granular form, but the lamellae are arranged with a long-range periodicity as indicated by a 'shoulder' in the SAXS curve with corresponding Bragg distance of about $20 \mathrm{~nm}$. Conversely, retrogradation at high temperature was shown to lead to formation of polymorphs $\mathrm{A}$ and $\mathrm{V}$ with no defined periodicity (Shamai, Bianco-Peled, \& Shimoni, 2003; Shamai et al., 2004).

In the follow-up study, Zabar, Shimoni, and Bianco-Peled (2008) used a similar approach to verify whether the effect of retrogradation temperature on the nanostructure of resistant starch observed for high amylose corn starch (Shamai et al., 2004) is valid for other starches such as normal corn and wheat starch. Their results indicated that retrogradation temperature of wheat starch did not have a significant effect on its nanostructure, whereas normal corn starch behaves comparably to the high amylose cultivar.

Zabar et al. (2009) subsequently studied the nanostructure of amylose-lipid complexes. Simple models such as "infinitely large flat particle" or a "stack of oriented lamellar layers" characterised by a single electron density failed to give a reasonable fit to the experimental data. A better fit was obtained using the "modified lamellar model". Zabar et al. (2009) concluded that increased levels of fatty acid unsaturation leads to the formation of ill-defined crystallites with decreased thermostability and spatial localizability, which extends even to the microscopic level of structure. In the follow-up study, Zabar, Lesmes, Katz, Shimoni, and Bianco-Peled (2010) broadened their previous research towards the study of nanostructure of amylose-lipid complexes using the acidification method, which is more suitable for food applications. Their results suggested that the acidification method leads to the formation of larger particles compared to the particles formed through the use of dimethylsulfoxide. Lopez-Rubio et al. (Lopez-Rubio, Clarke, Scherer, Topping, \& Gilbert, 2009) investigated changes in the nanostructure of low and high amylose maize starch as a result of short-chain fatty acid substitution. They reported an increase in long-range order with increasing chain length and decreases in contrast occurring for shorter acyl chain substitution.

Recently, we utilized SAXS to increase our understanding of the interactions between starch and lipids by exploring the behaviour of wheat starch pastes with added monoglycerides during repeated heating and cooling in the Rapid Visco Analyser (Blazek, Gilbert, \& Copeland, 2011). We employed the "two-phase non-particulate model" and the "power law plus Gaussian" function to fit the experimentally obtained SAXS curves from freeze-dried starch pastes. We showed that varying viscosity behaviour of pastes prepared with monoglycerides with different fatty acid chain lengths and unsaturation is likely to be related to the number, size and stability of complexes between amylose and monoglycerides, and the different melting temperatures of the lipids. We hypothesized that formation of individual amylose-lipid complexes and their aggregation into crystalline structures under constant shear and temperature fluctuations exerts an influence on aggregation and phase separation of paste components, with concomitant affects on the viscoelastic properties of the starch pastes (Blazek et al., 2011).

Our group has recently produced different starch structures through extrusion at low moisture content and subsequent storage using several maize and wheat starch varieties; the structural organization of the end-products was subsequently correlated with their enzyme digestibility (Chanvrier et al., 2007). Extrusion at low moisture content eliminated most of the crystallinity from native starches and the lamellar peak was replaced by a broad reflection although the lamellar peak was still apparent in some extruded samples. Storing the extruded samples at $60^{\circ} \mathrm{C}$ was shown to cause the broad reflection to extend over a narrower $q$ range, thus suggesting annealing and reorganization of

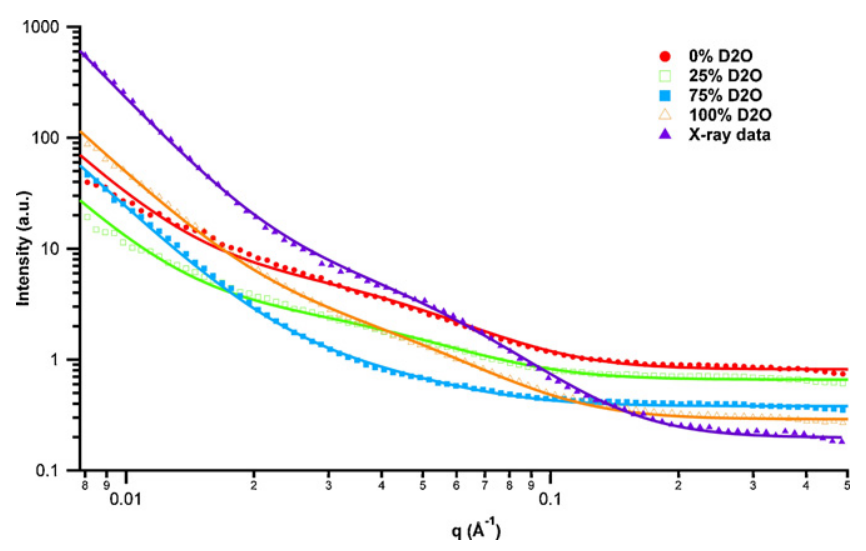

Fig. 7. SANS patterns of resistant starch formed from processed high-amylose maize starch in water. Four neutron solvent contrasts have been used: $0 \% \mathrm{D}_{2} \mathrm{O}$, (i.e. $100 \%$ $\mathrm{H}_{2} \mathrm{O}$ ), 25\% $\mathrm{D}_{2} \mathrm{O}: 75 \% \mathrm{H}_{2} \mathrm{O}, 75 \% \mathrm{D}_{2} \mathrm{O}: 25 \% \mathrm{H}_{2} \mathrm{O}$ and $100 \% \mathrm{D}_{2} \mathrm{O}$ along with an effective fifth contrast from SAXS. Dot points represent the experimental data that have been simultaneously fitted with a power law and two phase non-particulate model (solid lines).

Reproduced with permission from Lopez-Rubio and Gilbert (2009).

the crystals present, resulting in a more homogeneous crystalline structure. Digestion of the extruded samples was shown to shift the broad reflection towards higher $q$, i.e. shorter distances, which indicated that the distance between two consecutive crystalline regions became smaller, although the semicrystalline structure was still quite heterogeneous as indicated by the peak width. The increase in low-angle scattering for the sample stored at $60^{\circ} \mathrm{C}$ also indicated the formation of a larger scale structure (Chanvrier et al., 2007).

In the follow-up study, we studied morphological changes undergone by Gelose 80, upon extrusion at two different conditions and subsequent enzymatic digestion (Lopez-Rubio et al., 2007). The USAXS/SAXS curves of the starch structures collected under dry conditions, which were dominated by surface scattering, were fitted to a power law plus Gaussian function. Scattering data demonstrated increased surface roughness caused by the extrusion process compared to native starch granules. Scattering curves from samples in excess water were fitted to a 6 parameter model, which included a power law describing the low $q$ region and a two phase non-particulate model used to describe the scattering pattern of resistant starch. Extruded starches analysed in excess water displayed a broad scattering shoulder indicative of molecular order similar to one described by Chanvrier et al. (2007). Upon digestion, a new type of molecular organization with a characteristic repeat length of $5 \mathrm{~nm}$ was observed in the dry resistant starch fractions from the extruded high-amylose starch. The authors concluded that the resistance to digestion was not due to a specific structure, but it was related to the competition between the kinetics of retrogradation and enzymatic hydrolysis during digestion (LopezRubio et al., 2007). Interestingly, a scattering peak at 0.12-0.13 $\AA^{-1}$ similar to one observed by Lopez-Rubio et al. (2007) was observed by Cardoso and Westfahl (2010), who identified it as the second order reflection. Lopez-Rubio et al. (2007) attributed the appearance of this peak in the digested material to enhanced crystalline order upon digestion. Such an observation may also be related to a change of contrast due to physical density changes as a result of the digestion process although we note that this feature was observed only for processed starches. In the follow-up study, LopezRubio et al. (2008) studied the kinetics of digestion in further detail and reported that the molecular order develops during the actual digestion process.

Recently, we have performed, to the best of our knowledge, the first SANS studies on the resistant fraction of a processed high amylose starch. Fig. 7 shows the neutron patterns obtained at 4 different 
solvent conditions (varying the amount of $\mathrm{D}_{2} \mathrm{O} / \mathrm{H}_{2} \mathrm{O}$ ), together with the SAXS. The five scattering patterns have been simultaneously fitted to a 6 parameter function, including a power law, describing the low $q$ region and a two phase non-particulate model that has previously been observed to properly describe the scattering pattern of resistant starch (Lopez-Rubio et al., 2007). From the fits, it was possible to determine that the contrast match point occurs for a solvent containing $58.6 \% \mathrm{D}_{2} \mathrm{O}$, very similar to that of granular starch (Jenkins \& Donald, 1996), indicating that the scattering length differences of amorphous and crystalline phases are identical in native starch and its resistant starch fractions.

Zhang, Chen, Liu, and Wang (2010) employed SAXS to characterise the structure of starch from Canna edulis, which was microwave heat-moisture treated and subjected to enzymatic digestion. The authors reported that the intensities of SAXS curves increased with the increasing digestion time, indicating an increase in molecular order during the enzymatic digestion. Observed changes were ascribed to the difference of electrondensity and lamellar thickness distribution between the crystalline and amorphous materials caused by the preferential hydrolysis of amorphous material.

Analogously to pure native and processed starches, the same analysis approaches can be applied to starch-based products. In the early study by Jamroz and Pikus (1997), correlations between the scattering intensity and various physical properties of potato extrudates were described. It was demonstrated that a considerable amount of electron density inhomogeneities were formed in the products as a result of extrusion processing. Similarly, SAXS has been used to follow the staling process of bread products, during which significant changes at the nanoscale level were noted (Pikus, 2005; Pikus, Olszewska, \& Becal, 2006).

With regard to the ongoing interest in the nutritional benefits of slowly digestible and resistant starches, there are significant gaps in our knowledge as to which structural features are critical in governing the kinetics and the extent of starch digestion. For example, it remains unclear what role crystallinity plays during digestion, whether enzyme-resistant structures from in vitro and in vivo studies are present in the original food matrices or whether they are formed during digestion, and how effective currently used in vitro digestion methods are in simulating digestion of starch-based foods in humans. Answering these questions presents a challenge that requires a multidisciplinary approach combining various fields of expertise and scattering undoubtedly deserves its place in this approach.

\section{Concluding comments and future directions}

Genetic variation in starch structure and composition are of great importance to meet the requirements for different end uses. Even with the recent remarkable advances in biotechnology and bioinformatics, molecular genetics and comparative genomics, we still have an incomplete understanding of starch biosynthesis and there are many gaps in our knowledge of the relationship between the structure and function of starches (Jobling, 2004). As new possibilities to provide a more complete understanding of starch synthesis emerge, this important basic knowledge enables the development of new varieties used for food and feed, optimised in carbohydrate composition to the requirements of different consumers and addressing the needs for both fast and slow digestion (Rudi, Uhlen, Harstad, \& Munck, 2006).

Food systems are complex and dynamic multi-component and multi-phase systems and thus attempts for their characterisation must employ a broad arsenal of tools for biochemical, biophysical and structural investigations and use principles from other fields such as polymer science (Limbach \& Kremer, 2006). Attempts to apply techniques traditionally not widely used in food science provide fascinating challenges and opportunities for modern food materials science. Apart from potentially damaging synchrotron radiation, $\mathrm{X}$-rays and neutrons are non-destructive in their nature with respect to the sample structure and offer a number of advantages such as their high penetration capability (particularly the case for neutrons) allowing bulk property determination and their sensitivity to small structural changes. Additionally, these techniques can be applied to complex sample environments and in situ investigations thus allowing study of systems under realistic conditions including hydrated states or suspensions. Small-angle scattering offers the unique opportunity to probe materials on the length scales between the capabilities of modern crystallography and microscopy, thus bridging the gap in spatial resolution between these two worlds enabling a more complete understanding of starch to be attained.

With more basic scientific methods entering food technology, it becomes more apparent that small-angle scattering techniques deserve their place in the multi-technique approach, which aims to understand the structural mechanisms governing starch processing and digestion, and makes it possible to design and select those processes which render desirable structural morphologies (Chanvrier et al., 2007; Limbach \& Kremer, 2006; Lopez-Rubio et al., 2007; Redgwell \& Fischer, 2005).

\section{References}

Agamalyan, M. M., Evmemenko, G. A., Vilesov, A. D., Frenkel, S. Ya., Zgonnik, V. N., Vinogradova, L. V., et al. (1992). Small-angle neutron diffraction study of block copolymer superstructure. Polymer, 33, 2542-2547.

Aggarwal, P., \& Dollimore, D. (1998). A thermal analysis investigation of partially hydrolyzed starch. Thermochimica Acta, 319, 17-25.

Annison, G., \& Topping, D. L. (1994). Nutritional role of resistant starch: Chemical structure versus physiological function. Annual Review of Nutrition, 14, 297-320.

Avnir, D. (Ed.). (1989). The fractal approach to heterogeneous chemistry. Chichester, England: Wiley.

Baker, A. A., Miles, M. J., \& Helbert, W. (2001). Internal structure of the starch granule revealed by AFM. Carbohydrate Research, 330, 249-256.

Balta-Calleja, F. J., \& Vonk, G. G. (1989). X-ray scattering of synthetic polymers. New York: Elsevier Science.

Beaucage, G. (1996). Small-angle scattering from polymeric mass fractals of arbitrary mass-fractal dimension. Journal of Applied Crystallography, 29, 13-146.

Belton, P. (2007). The chemical physics of food. Oxford, UK: Blackwell Publishing Ltd.

Blanshard, J. M. V. (1987). Starch granule structure and function: A physicochemical approach. In T. Galliard (Ed.), Starch: Properties and potential (pp. 16-54). Chichester: John Wiley and Sons.

Blanshard, J. M. V., Bates, D. R., Muhr, A. H., Worcester, D. L., \& Higgins, J. S. (1984). Small angle neutron scattering studies of starch granule structure. Carbohydrate Polymers, 4, 427-442.

Blazek, J., \& Gilbert, E. P. (2010). The effect of enzymatic hydrolysis on native starch granule structure. Biomacromolecules, 11, 3275-3289.

Blazek, J., Gilbert, E. P., \& Copeland, L. Effects of lipids on pasting properties of wheat starch during repeated heating and cooling. Journal of Cereal Science, accepted 27th February 2011.

Blazek, J., Salman, H., Lopez-Rubio, A., Gilbert, E. P., Hanley, T., \& Copeland, L. (2009). Structural characterization of wheat starch granules differing in amylose content and functional characteristics. Carbohydrate Polymers, 75, 705-711.

Bocharnikova, I., Wasserman, L. A., Krivandin, A. V., Fornal, J., Baszczak, W., Chernykh, V. Y., et al. (2003). Structure and thermodynamic melting parameters of wheat starches with different amylose content. Journal of Thermal Analysis and Calorimetry, 74, 681-695.

Brumberger, H. (1995). Modern aspects of small-angle scattering. Leiden, Netherlands: Kluwer Academic Publishers.

Buleon, A., Gerard, C., Riekel, C., Vuong, R., \& Chnazy, H. (1998). Details of the crystalline ultrastructure of $\mathrm{C}$-starch granules revealed by synchrotron microfocus mapping. Macromolecules, 31, 6605-6610.

Buleon, A., Pontoire, B., Riekel, C., Chanzy, H., Helbert, W., \& Vuong, R. (1997). Crystalline ultrastructure of starch granules revealed by synchrotron radiation microdiffraction mapping. Macromolecules, 30, 3952-3954.

Burrell, M. M. (2003). Starch: The need for improved quality or quantity - An overview. Journal of Experimental Botany, 54, 451-456.

Cameron, R. E., \& Donald, A. M. (1992). A small-angle X-ray scattering study of the annealing and gelatinisation of starch. Polymer, 33, 2628-2635.

Cameron, R. E., \& Donald, A. M. (1993a). A small-angle X-ray scattering study of the absorption of water into the starch granule. Carbohydrate Research, 244, 225-236.

Cameron, R. E., \& Donald, A. M. (1993b). A small-angle X-ray scattering study of starch gelatinization in excess and limiting water. Journal of Polymer Science Part B: Polymer Physics, 31, 1197-1203. 
Cardoso, M. B., \& Westfahl, H., Jr. (2010). On the lamellar width distributions of starch. Carbohydrate Polymers, 81, 21-28.

Cassidy, A., Bingham, S. A., \& Cummings, J. H. (1994). Starch intake and colorectal cancer risk: An international comparison. British Journal of Cancer, 69, 937-942.

Chanvrier, H., Uthayakumaran, S., Appelqvist, I. A. M., Gildey, M. J., Gilbert, E. P., \& Lopez-Rubio, A. (2007). Influence of storage conditions on the structure, thermal behavior, and formation of enzyme-resistant starch in extruded starches. Journal of Agricultural and Food Chemistry, 55, 9883-9890.

Ciesla, K, Zoltowski, T., \& Mogilevski, L. Y. (1992). SAXS investigations of structural changes after gamma ray irradiation of potato starch and starch suspensions. Starch/Starke, 11, S419-422.

Colonna, P., \& Mercier, C. (1985). Gelatinization and melting of maize starches with normal and high amylose phenotypes. Phytochemistry, 24, 1667-1674.

Copeland, L., Blazek, J., Salman, H., \& Tang, M. C. (2009). Form and functionality of starch. Food Hydrocolloids, 23, 1527-1534.

Daniels, D. R., \& Donald, A. M. (2003). An improved model for analysing the smallangle X-ray scattering of starch granules. Biopolymers, 69, 165-175.

Daniels, D. R., \& Donald, A. M. (2004). Soft material characterization of the lamellar properties of starch: Smectic side-chain liquid-crystalline polymeric approach. Macromolecules, 37, 11312-11318.

Debye, P., \& Bueche, A. M. (1949). Scattering by an inhomogeneous solid. Journal of Applied Physics, 20, 518-525.

Donald, A. M. (2001). Plasticisation and self-assembly in starch granules. Cereal Chemistry, 78, 307-314.

Donald, A. M., Kato, K. L., Perry, P. A., \& Waigh, T. A. (2001). Scattering studies of the internal structure of starch granules. Starch/Starke, 53, 504-512.

Donovan, J. W. (1979). Phase transitions of the starch-water system. Biopolymers, $18,263-275$

Eliasson, A.-C. (2004). Starch in food: Structure function and applications. Cambridge/Boca Raton: Woodhead Publishing Limited/CRC Press LLC.

Franks, A. (1955). An optically focusing X-ray diffraction camera. Proceedings of the Physical Society, Section B, 68, 1054-1064.

Franks, A. (1958). Some developments and applications of microfocus X-ray diffraction techniques. British Journal of Applied Physics, 9, 349-352.

Furuno, T., Sasabe, H., \& Ikegami, A. (1987). A small-angle X-ray camera using a twodimensional multiwire proportional chamber.Journal of Applied Crystallography, $20,16-22$.

Gallant, D. J., Bouchet, B., \& Baldwin, P. M. (1997). Microscopy of starch: Evidence of a new level of granule organization. Carbohydrate Polymers, 32,177-191.

Gallant, D. J., Bouchet, B., Buleon, A., \& Perez, S. (1992). Physical characteristics of starch granules and susceptibility to enzymatic degradation. European Journal of Clinical Nutrition, 46, S3-S16.

Gebhardt, R., Hanfland, H., Mezouar, M., \& Riekel, C. (2007). High-pressure potato starch granule gelatinization: Synchrotron radiation micro-SAXS/WAXS using a diamond anvil cell. Biomacromolecules, 8, 2092-2097.

Glatter, O., \& Kratky, O. (1982). Small-angle X-ray scattering. New York: Academic Press.

Guinier, A., \& Fournet, G. (1955). Small-angle X-ray scattering. John Wiley publishing.

Hammouda, B. (2008). Probing nanoscale structures - The SANS toolbox. http://www.ncnr.nist.gov/staff/hammouda/the_SANS_toolbox.pdf

Haubold, H.-G., Gebhardt, R., Buth, G., \& Goerigk, G. G. (1994). Structural characterisation of compositional and density inhomogeneities. In G. Materlik, C. F. Sparks, $\&$ K. Fischer (Eds.), Resonant anomalous $X$-ray scattering, theory and applications (pp. 295-304). Elsevier Science.

Hendricks, R. W. (1978). The ORNL 10-meter small angle X-ray scattering camera. Journal of Applied Crystallography, 11, 15-30.

Higgins, J. S., \& Benoit, H. (1994). Polymers and neutron scattering. Oxford series on neutron scattering. New York: Oxford University Press.

Higgins, J. S., \& Benoit, H.C. (1997). Polymers and neutron scattering. Oxford University Press., p. 124.

Hoover, R., \& Manuel, H. (1995). A comparative study of the physicochemical properties of starches from two lentil cultivars. Food Chemistry, 53, 275-284.

Hylla, S., Gostner, A., Dusel, G., Anger, H., Bartram, H. P., Christl, S. U., et al. (1998). Effects of resistant starch on the colon in healthy volunteers: Possible implications for cancer prevention. American Journal of Clinical Nutrition, 67, 136-142.

I'Anson, K. J., Miles, M. J., Morris, V. J., \& Ring, S. G. (1988). A study of amylose gelation using a synchrotron X-ray source. Carbohydrate Polymers, 8, 45-53.

Jacobs, H., Mischenko, N., Koch, M. H. J., Eerlingen, R. C., Delcour, J. A., \& Reynaers, H. (1998). Evaluation of the impact of annealing on gelatinisation at intermediate water content of wheat and potato starches: A differential scanning calorimetry and small angle X-ray scattering study. Carbohydrate Research, 306, 1-10.

Jamroz, J., \& Pikus, S. (1997). New aspects of small angle X-ray scattering investigations on potato extrudates. Italian Journal of Food Science, 3, 205-214.

Jenkins, P. J., Cameron, R. E., \& Donald, A. M. (1993). A universal feature in the structure of starch granules from different botanical sources. Starch/Starke, 45 , 417-420.

Jenkins, P. J., Cameron, R. E., Donald, A. M., Bras, W., Derbyshire, G. E., Mant, G. R., et al. (1994). In situ simultaneous small and wide angle X-ray scattering: A new technique to study starch gelatinization. Journal of Polymer Science Part B: Polymer Physics, 32, 1579-1583.

Jenkins, P. J., \& Donald, A. M. (1995). The influence of amylose on starch granule structure. International Journal of Biological Macromolecules, 17, 315-321.

Jenkins, P. J., \& Donald, A. M. (1996). Application of small-angle neutron scattering to the study of the structure of starch granules. Polymer, 37, 5559-5568.

Jenkins, P. J., \& Donald, A. M. (1997a). The effect of acid hydrolysis on native starch granule structure. Starch/Starke, 7/8, S262-267.
Jenkins, P. J., \& Donald, A. M. (1997b). Breakdown of crystal structure in potato starch during gelatinization. Journal of Applied Polymer Science, 66, 225-232.

Jenkins, P. J., \& Donald, A. M. (1998). Gelatinisation of starch - A combined WAXS/SAXS/DSC and SANS study. Carbohydrate Research, 308, 133-147.

Jobling, S. (2004). Improving starch for food and industrial applications. Current Opinion in Plant Biology, 7, 210-218.

Koberstein, J. T., \& Stein, R. S. (1983). Small-angle X-ray scattering measurements of diffuse phase boundary thicknesses in segmented polyurethane elastomers. Journal of Polymer Science, 21, 2181-2200.

Koch, M. H. J. (2006). X-ray scattering of non-crystalline biological systems using synchrotron radiation. Chemical Society Reviews, 35, 123-133.

Koroteeva, D. A., Kiseleva, V.I., Krivandin, A. V., Shatalova, O. V., Błaszczak, W., Bertoft E., et al. (2007). Structural and thermodynamic properties of rice starches with different genetic background. Part 2. Defectiveness of different supramolecular structures in starch granules. International Journal of Biological Macromolecules, $41,534-547$.

Koroteeva, D. A., Kiseleva, V. I., Sriroth, K., Piyachomkwan, K., Bertoft, E., Yuryev, P. V., et al. (2007). Structural and thermodynamic properties of rice starches with different genetic background. Part 1. Differentiation of amylopectin and amylose defects. International Journal of Biological Macromolecules, 41, 391-403.

Kozlov, S. S., Blennow, A., Krivandin, A. V., \& Yuryev, V. P. (2007). Structural and thermodynamic properties of starches extracted from GBSS and GWD suppressed potato lines. International Journal of Biological Macromolecules, 40 449-460.

Kozlov, S. S., Krivandin, A. V., Shatalova, O. V., Noda, T., Bertoft, E., Fornal, J., et al. (2007). Structure of starches exctracted from near-isogenic wheat lines. Part II. Molecular organization of amylopectin clusters. Journal of Thermal Analysis and Calorimetry, 87, 575-584.

Laity, P. R., \& Cameron, R. E. (2010). Changes in small-angle X-ray scattering during powder compaction - An explanation based on granule deformation. Powder Technology, 198, 404-411.

Limbach, H. J., \& Kremer, K. (2006). Multi-scale modelling of polymers: Perspectives for food materials. Trends in Food Science \& Technology, 17, 215-219.

Lopez-Rubio, A., Clarke, J. M., Scherer, B., Topping, D. L., \& Gilbert, E. P. (2009). Structural modifications of granular starch upon acylation with short-chain fatty acids. Food Hydrocolloids, 23, 1940-1946.

Lopez-Rubio, A., Flanagan, B. M., Shrestha, A. K., Gidley, M. J., \& Gilbert, E. P. (2008). Molecular rearrangement of starch during in vitro digestion: Toward a better understanding of enzyme resistant starch formation in processed starches. Biomacromolecules, 9, 1951-1958.

Lopez-Rubio, A., \& Gilbert, E. P. (2009). Neutron scattering: A natural tool for food science and technology. Trends in Food Science E Technology, 20, 576-586.

Lopez-Rubio, A., Htoon, A., \& Gilbert, E. P. (2007). Influence of extrusion and digestion on the nanostructure of high-amylose maize starch. Biomacromolecules, 8 , 1564-1572.

Lovesey, S. W. (1984). The theory of neutron scattering from condensed matter Oxford University Press.

Mandelbrot, B. B. (1977). Fractals: Form, chance and dimension. New York: Freeman.

Mandelbrot, B. B. (1983). The fractal geometry of nature. New York: Freeman.

Martin, J. E., \& Hurd, A. J. (1987). Scattering from fractals. Journal of Applied Crystallography, 20, 61-78.

Matveev, Y. I., Elankin, N. I., Kalistratova, E. N., Danilenko, A. N., Niemann, C., \& Yuryev, V. P. (1998). Estimation of contributions of hydration and glass transition to heat capacity changes during melting of native starches at excess water. Starch/Starke $50,141-147$.

McArdle, C. B. (Ed.). (1989). Side chain liquid crystal polymers. London: Blackie and Son Ltd.

Mezzenga, R., Schurtenberger, P., Burbidge, A., \& Michel, M. (2005). Understanding foods as soft materials. Nature Materials, 4, 729-740.

Muhr, A. H., Blanshard, J. M. V., \& Bates, D. R. (1984). The effect of lintnerisation on wheat and potato starch granules. Carbohydrate Polymers, 4, 399-425.

Müller, J. J., Gernat, C., Schulz, W., Müller, E. C., Vorwerg, W., \& Damaschun, G. (1995). Computer simulations of X-ray scattering curves: Gelation and crystallization process in amylose solutions. Biopolymers, 35, 271-288.

Murthy, N. S., Curran, S. A., Aharoni, S. M., \& Minor, H. (1991). Premelting crystalline relaxations and phase transitions in nylon 6 and 6,6. Macromolecules, 24 3215-3220.

Nishiyama, Y., Putaux, J. L., Montesanti, N., Hazemann, J. L., \& Rochas, C. (2010). B $\rightarrow$ A allomorphic transition in native starch and amylose spherocrystals monitored by in situ synchrotron X-ray diffraction. Biomacromolecules, 11, 76-87.

Noda, T., Isono, N., Krivandin, A. V., Shatalova, O. V., Błaszczak, W., \& Yuryev, V. P. (2009). Origin of defects in assembled supramolecular structures of sweet potato starches with different amylopectin chain-length distribution. Carbohydrate Polymers, 76, 400-409.

Oostergetel, G. T., \& van Bruggen, E. F. J. (1993). The crystalline domains in potato starch granules are arranged in a helical fashion. Carbohydrate Polymers, 21 $7-12$.

Parker, Mary L., Kirby, Andrew R., \& Morris, Victor J. (2008). In situ Imaging of Pea Starch in Seeds. Food Biophysics, 3, 66-76.

Peng, L., Zhongdong, L., \& Kennedy, J. F. (2007). The study of starch nano-unit chains in the gelatinization process. Carbohydrate Polymers, 68, 360-366.

Perry, P. A., \& Donald, A. M. (2000a). The role of plasticization in starch granule assembly. Biomacromolecules, 1, 424-432.

Perry, P. A., \& Donald, A. M. (2000b). SANS study of the distribution of water within starch granules. International Journal of Biological Macromolecules, 28, 31-39. 
Perry, P. A., \& Donald, A. M. (2002). The effect of sugars on the gelatinisation of starch. Carbohydrate Polymers, 49, 155-165.

Pikus, S. (2005). Small-angle X-ray scattering (SAXS) studies of the structure of starch and starch products. Fibres \&' Textiles in Eastern Europe, 13, 82-86.

Pikus, S., Olszewska, E., \& Becal, M. (2006). Investigation of the staling process of bread using the small-angle X-ray scattering (SAXS) method. Flavour and Fragrance Journal, 21, 37-41.

Popov, D., Buleon, A., Burghammer, M., Chanzy, H., Montesanti, N., Putaux, J.-L., et al. (2009). Crystal structure of A-amylose: A revisit from synchrotron microdiffraction analysis of single crystals. Macromolecules, 42, 1167-1174.

Redgwell, R. J., \& Fischer, M. (2005). Dietary fiber as a versatile food component: An industrial perspective. Molecular Nutrition \& Food Research, 49, 421-535.

Ridout, M. J., Parker, M. L., Hedley, C. L., Bogracheva, T. Y., \& Morris, V.J. (2004). Atomic force microscopy of pea starch: Origins of image contrast. Biomacromolecules, 5 , 1519-1527.

Rudi, H., Uhlen, A. K., Harstad, O. M., \& Munck, L. (2006). Genetic variability in cereal carbohydrate compositions and potentials for improving nutritional value. Animal Feed Science and Technology, 130, 55-65.

Saibene, D., \& Seetharaman, K. (2010). Amylose involvement in the amylopectin clusters of potato starch granules. Carbohydrate Polymers, 82, 376-383.

Salman, H., Blazek, J., Lopez-Rubio, A., Gilbert, E. P., Hanley, T., \& Copeland, L. (2009). Structure-function relationships in A and B granules from wheat starches of similar amylose content. Carbohydrate Polymers, 75, 420-427.

Sanderson, J. S., Daniels, R. D., Donald, A. M., Blennow, A., \& Engelsen, S. B. (2006). Exploratory SAXS and HPAEC-PAD studies of starches from diverse plant genotypes. Carbohydrate Polymers, 64, 433-443.

Sanguansri, P., \& Augustin, M. A. (2006). Nanoscale materials development - A food industry perspective. Trends in Food Science E Technology, 17, 547-556.

Schmidt, P. W. (1991). Small-angle scattering studies of disordered, porous and fractal systems. Journal of Applied Crystallography, 24, 414-435.

Schmidt-Rohr, K. (2007). Simulation of small-angle scattering curves by numerical Fourier transformation. Journal of Applied Crystallography, 40, 16-25.

Shamai, K., Bianco-Peled, H., \& Shimoni, E. (2003). Polymorphism of resistant starch type III. Carbohydrate Polymers, 54, 363-369.

Shamai, K., Shimoni, E., \& Bianco-Peled, H. (2004). Small angle X-ray scattering of resistant starch type III. Biomacromolecules, 5, 219-223.

Siddique, K. (2008). The food and agricultural research challenge. http://www.sciencealert.com.au/opinions/20081803-17064.html

Sterling, C. (1962). A low angle spacing in starch. Journal of Polymer Science, 56, S10-S12.

Strobl, G. R., \& Schneider, M. (1980). Direct evaluation of the electron density correlation function of partially crystalline polymers. Journal of Polymer Science: Polymer Physics Edition, 18, 1343-1359.

Suzuki, T., Chiba, A., \& Yano, T. (1997). Interpretation of small-angle X-ray scattering from starch on the basis of fractals. Carbohydrate Polymers, 34, 357-363.

Svergun, D. I., \& Koch, M. H. J. (2003). Small-angle scattering studies of biological macromolecules in solution. Reports on Progress in Physics, 66, 1735-1782.

Tang, H., Mitsunaga, T., \& Kawamura, Y. (2006). Molecular arrangement in blocklets and starch granule architecture. Carbohydrate Polymers, 63, 555-560.

Tester, R. F. (1997). Starch: The polysaccharide fractions. In P. J. Frazier, A. M. Donald, \& P. Richmond (Eds.), Starch: Structure and functionality (pp. 163-171). Cambridge: The Royal Society of Chemistry.

Tester, R. F., Karkalas, J., \& Qi, X. (2004). Starch - Composition, fine structure and architecture. Journal of Cereal Science, 39, 151-165.

Thys, R. C. S, Westfahl, H., Jr., Norena, C. P. Z., Marczak, L. D. F., Silveira, N. P., \& Cardoso, M. B. (2008). Effect of the alkaline treatment on the ultrastructure of C-type starch granules. Biomacromolecules, 9, 1894-1901.

Ubbink, J., \& Mezzenga, R. (2006). Delivery of functionality in complex food systems: Introduction. Trends in Food Science E Technology, 17, 194-195.

Vaananen, T., Ikonen, T., Jokela, K., Serimaa, R., Pietila, L., \& Pehu, E. (2003). X-ray scattering study on potato (Solanum tuberosum L.) cultivars during winter storage. Carbohydrate Polymers, 54, 499-507.

Vandeputte, G. E., \& Delcour, J. A. (2004). From sucrose to starch granule to starch physical behaviour: A focus on rice starch. Carbohydrate Polymers, 58, 245-266.
Verma, R. K., Marand, H., \& Hsiao, B. S. (1996). Morphological changes during secondary crystallization and subsequent melting in poly(ether ether ketone) as studied by real time small angle X-ray scattering. Macromolecules, 29, 7767-7775.

Vermeylen, R., Derycke, V., Delcour, J. A., Goderis, B., Reynaers, H., \& Koch, M. H. J. (2006a). Gelatinization of starch in excess water: Beyond the melting of lamellar crystallites. A combined wide- and small-angle X-ray scattering study. Biomacromolecules, 7, 2624-2630.

Vermeylen, R., Derycke, V., Delcour, J. A., Goderis, B., Reynaers, H., \& Koch, M. H. J. (2006b). Structural transformations during gelatinization of starches in limited water: Combined wide- and small-angle X-ray scattering study. Biomacromolecules, 7, 1231-1238.

Vermeylen, R., Goderis, B., Reynaers, H., \& Delcour, J. A. (2004). Amylopectin molecular structure reflected in macromolecular organization of granular starch. Biomacromolecules, 5, 1775-1786.

Vonk, C. G. (1973). Investigation of non-ideal two-phase polymer structures by small-angle X-ray scattering. Journal of Applied Crystallography, 6, 81-86.

Vonk, C. G. (1978). The small-angle scattering of distorted lamellar structures. Journal of Applied Crystallography, 11, 541-546.

Waigh, T. A., Donald, A. M., Heidelbach, F., Riekel, C., \& Gidley, M. J. (1999). Analysis of the native structure of starch granules with small angle X-ray microfocus scattering. Biopolymers, 49, 91-105.

Waigh, T. A., Gidley, M. J., Komanshek, B. U., \& Donald, A. M. (2000). The phase transformations in starch during gelatinisation: A liquid crystalline approach. Carbohydrate Research, 328, 165-176.

Waigh, T. A., Hopkinson, I., Donald, A. M., Butler, M. F., Heidelbach, F., \& Riekel, C. (1997). Analysis of the native structure of starch granules with X-ray microfocus diffraction. Macromolecules, 30, 3813-3820.

Waigh, T. A., Jenkins, P. J., \& Donald, A. M. (1996). Quantification of water in carbohydrate lamellae using SANS. Faraday Discussions, 103, 325-337.

Waigh, T. A., Kato, K. L., Donald, A. M., Gidley, M. J., \& Riekel, C. (2000). Side-chain liquid crystalline model for starch. Starch/Starke, 52, 252-260.

Waigh, T. A., Perry, P., Riekel, C., Gidley, M., \& Donald, A. M. (1998). Chiral side-chain liquid-crystalline properties of starch. Macromolecules, 31, 7980-7984.

Wang, Z. G., Hsiao, B. S., \& Murthy, N. S. (2000). Comparison of intensity profile analysis and correlation function methods for studying the lamellar structures of semicrystalline polymers using small angle X-ray scattering. Journal of Applied Crystallography, 33, 690-694.

Wenig, W., \& Bramer, R. (1978). Significance of mean sample density for quantitative interpretation of small-angle X-ray-scattering of partially crystalline polymers. Colloid and Polymer Science, 256, 125-132.

Yuryev, V. P., Krivandin, A. V., Kiseleva, V. I., Wasserman, L. A., Genkina, N. K., Fornal, J., et al. (2004). Structural parameters of amylopectin clusters and semi-crystalline growth rings in wheat starches with different amylose content. Carbohydrate Research, 339, 2683-2691.

Yuryev, V. P., Tomasik, P., \& Bertoft, E. (2007). Starch: Achievements in understanding of structure and functionality. New York: Nova Science Publishers.

Zabar, S., Lesmes, U., Katz, I., Shimoni, E., \& Bianco-Peled, H. (2009). Studying different dimensions of amylose-long chain fatty acid complexes: Molecular, nano and micro level characteristics. Food Hydrocolloids, 23, 1918-1925.

Zabar, S., Lesmes, U., Katz, I., Shimoni, E., \& Bianco-Peled, H. (2010). Structural characterization of amylose-long chain fatty acid complexes produced via the acidification method. Food Hydrocolloids, 24, 347-357.

Zabar, S., Shimoni, E., \& Bianco-Peled, H. (2008). Development of nanostructure in resistant starch type III during thermal treatments and cycling. Macromolecular Bioscience, 8, 163-170.

Zhang, G., Ao, Z., \& Hamaker, B. R. (2006). Slow digestion property of native cereal starches. Biomacromolecules, 7, 3252-3258.

Zhang, G., Venkatachalam, M., \& Hamaker, B. R. (2006). Structural basis for the slow digestion property of native cereal starches. Biomacromolecules, 7, 3259-3266.

Zhang, J., Chen, F., Liu, F., \& Wang, Z. W. (2010). Study on structural changes of microwave heat-moisture treated resistant Canna edulis Ker starch during digestion in vitro. Food Hydrocolloids, 24, 27-34. 